\title{
Epogam evening primrose oil treatment in atopic dermatitis and asthma
}

Paediatric Clinic, Health Centre Gripen, Karlstad, Sweden C-A Hederos

Department of Paediatrics, Central Hospital, Karlstad, Sweden

A Berg

Correspondence and request for reprints to:

Dr Carl-Axel Hederos,

Barn-och

Ungdomsmedicinmottagningen

Vårdcentralen, Gripen,

Box 547, 65112 Karlstad,

Sweden.

Accepted 19 July 1996

Carl-Axel Hederos, Anders Berg

\begin{abstract}
Essential fatty acids are claimed to have positive effects in atopic diseases. In a double blind, placebo controlled, parallel group study 58 out of 60 children, with atopic dermatitis and the need for regular treatment with topical skin steroids, completed a 16 weeks' treatment period with either Epogam evening primrose oil or placebo capsules. Twenty two of these subjects also had asthma. The parents used diaries to record symptom scores and concomitant medication. Peak expiratory flow was measured and disease activity was monitored by the clinician every four weeks. The plasma concentrations of essential fatty acids increased significantly in the group treated with Epogam capsules. The study demonstrated significant improvements of the eczema symptoms but no significant difference was found between the placebo and the Epogam groups. No therapeutic effect was shown on asthma symptoms or fidget.

(Arch Dis Child 1996;75:494-497)
\end{abstract}

Keywords: essential fatty acids, atopic dermatitis, asthma.

In many countries Epogam evening primrose oil containing $n-6$ series essential fatty acids is licensed for use in atopic dermatitis. The effective substance is believed to be gammalinolenic acid (GLA). It has been proposed that patients with atopic dermatitis have a defective functioning of the delta-6-desaturase enzyme. This results in lower concentrations of GLA, dihomogammalinolenic acid (DGLA), arachidonic acid, and of their products prostaglandin $E_{1}$ and $E_{2}\left(P_{1} E_{1}, P G E_{2}\right)$. It is claimed that low concentrations of $\mathrm{PGE}_{1}$ and $\mathrm{PGE}_{2}$ play a major part in the origin of atopic diseases. Essential fatty acids are necessary for normal epithelial permeability.

Clinical trials have shown variable results and its use in atopic dermatitis is controversial. ${ }^{1-4}$ GLA is not licensed for use in Sweden but even so one study showed that $22 \%$ of children with moderate or severe atopic dermatitis used alternative treatments, mainly GLA preparations. ${ }^{5}$ As many as $68 \%$ of children with atopic dermatitis also have asthma, ${ }^{6}$ and on theoretical grounds the respiratory symptoms might also be influenced by essential fatty acid treatment. ${ }^{7}$ The aim of this investigation was to study the effect of GLA in children with atopic dermatitis and also the effect on asthma in those children who suffered from both atopic dermatitis and asthma.

\section{Patients and methods}

PATIENTS

The study was a double blind, randomised, placebo controlled trial. It was parallel in design with a 16 weeks' treatment period. Sixty children between 1-16 years of age with atopic dermatitis who met the criteria of Hanifin and Rajka, ${ }^{8}$ and who needed regular treatment with topical steroids, were recruited from two outpatient clinics. Twenty two of these patients also had asthma. Patients were examined at baseline and thereafter every fourth week. Approval was obtained from the regional ethical committee and the National Swedish Board of Health and Welfare. The parents' consent was obtained.

\section{TREATMENT}

The children received either Epogam capsules (containing $500 \mathrm{mg}$ evening primrose oil providing $40 \mathrm{mg}$ GLA with $10 \mathrm{mg}$ vitamin E) or identical placebo gelatin capsules containing $500 \mathrm{mg}$ sunflower oil with $10 \mathrm{mg}$ vitamin $\mathrm{E}$ (Scotia Pharmaceuticals Ltd). A randomisation list was provided that allocated patients in blocks of two. Dosage was according to age: children 1-12 years of age were given four capsules twice daily, those over 12 years six capsules twice daily. Younger children who were unable to swallow capsules were recommended to cut the capsules open. To check for compliance the unused capsules were counted at each visit, the parents were questioned, and blood samples were taken at weeks 0 and 16 for fatty acid analyses. The usual treatment for symptoms of eczema and asthma was allowed and the amounts of concurrent medication were recorded at each visit.

\section{EVALUATION}

At each visit the clinician made a graded assessment, using a visual analogue scale $(0=$ normal, $100=$ worst ever seen) of the following parameters: redness, dryness, crusts, excoriation/itch, scaling, lichenification, fidget, overall impression of condition, area of involvement. The grading of symptoms was a global assessment to include all affected sites. In the patients with asthma the clinicians measured peak flow and made a graded assessment of the overall impression of the condition using the visual analogue scale.

The quantities of topical steroids, antihistamines, and asthma medication dispensed and returned were recorded. Parents were provided 
Table 1 Eczema patients: baseline profiles

\begin{tabular}{|c|c|c|}
\hline & Epogam $(n=30)$ & Placebo $(n=30)$ \\
\hline Male/female & $13 / 17$ & $13 / 17$ \\
\hline Mean (range) age (years) & $7.5(1-14)$ & $8.6(2-16)$ \\
\hline \multicolumn{3}{|l|}{ Treatment (No) } \\
\hline Group I or II steroid & 24 & 22 \\
\hline Group III or IV steroid & 6 & 8 \\
\hline Antihistamine & 24 & 19 \\
\hline $\begin{array}{l}\text { Mean age at onset of eczema } \\
\text { (years) }\end{array}$ & 0.9 & 1.6 \\
\hline Mean total IgE (kU/l) & 322 & 422 \\
\hline $\begin{array}{l}\text { No with skin prick test } \\
\text { positive }\end{array}$ & 21 & 23 \\
\hline $\begin{array}{l}\text { Eczema severity } \\
\text { (mild:moderate:severe) }\end{array}$ & 5:18:6 & $4: 23: 3$ \\
\hline \multicolumn{3}{|l|}{$\begin{array}{l}\text { Mean (SD) pretrial parent } \\
\text { score }\end{array}$} \\
\hline Itch & $43.1(30.0)$ & $35.4(24.3)$ \\
\hline Global severity & $32.3(21.8)$ & $23.6(12.4)$ \\
\hline \multicolumn{3}{|l|}{$\begin{array}{l}\text { Mean (SD) pretrial clinician } \\
\text { score }\end{array}$} \\
\hline Itch & $47.7(19.2)$ & $42.1(16.9)$ \\
\hline Global severity & $41.9(16.5)$ & $37.0(13.4)$ \\
\hline
\end{tabular}

with a diary booklet in which they made weekly assessments of the same parameters as the clinician except lichenification and the area involved. The quality of sleep was included. In children with asthma the peak flow and overall assessment were recorded and also the number of days with extra asthma medication. In addition to the recorded scores, clinician and parent global scores were calculated as the mean of the available scores concerning the eczema. Routine haematological and biochemical analyses including total IgE and essential fatty acids were analysed. Initially a skin prick test with a standard panel of allergens was made.

\section{STATISTICAL METHODS}

Both intention to treat and per protocol analyses were conducted. Treatment comparisons were made at week 16 of the mean change from week 0 using the two sample test for all variables except steroid usage for which the $\chi^{2}$ test for trend was used. The primary efficacy measure was the change from baseline in parent assessment of itch. A significance level of $5 \%$ was used and estimates of treatment differences are given with $95 \%$ confidence intervals. Methods based on normal distribution were used for the analyses of severity score.
Table 2 Asthma patients: baseline profiles

\begin{tabular}{|c|c|c|}
\hline & $\begin{array}{l}\text { Epogam } \\
(n=12)\end{array}$ & $\begin{array}{l}\text { Placebo } \\
(n=10)\end{array}$ \\
\hline Male/female & $7 / 5$ & $6 / 4$ \\
\hline Mean (range) age (years) & $9.3(4-14)$ & $10.9(3-16)$ \\
\hline$\beta 2$-agonist (inhalation) & 11 & 10 \\
\hline $\begin{array}{l}\text { Steroid (inhalation:maximum } \\
\text { dose } 0.2 \mathrm{mg} \times 2 \text { ) }\end{array}$ & 3 & 4 \\
\hline Sodium cromoglycate & 2 & 3 \\
\hline $\begin{array}{l}\text { Positive RAST or skin prick } \\
\text { test }\end{array}$ & 12 & 10 \\
\hline
\end{tabular}

RAST = radioallergosorbent test.

\section{Results}

Sixty children with eczema were recruited into the study. Thirty received Epogam and 30 placebo capsules. The treatment groups were well matched at baseline concerning demographic data and eczema severity (table 1), although there was a tendency for the Epogam group to be more severely affected.

Twenty two of the eczema patients also had current asthma problems and their baseline profiles were also well matched (table 2). Two patients in the Epogam group withdrew during the course of the study, one boy after only three days as he could not accept the taste of the capsules. The other patient completed eight weeks of treatment but then refused to undergo further assessments. Available data were included in analyses for these patients up to the point of withdrawal.

The clinical efficacy according to parents' and clinicians' assessments of eczema after 16 weeks' treatment are shown in tables 3 and 4 .

Both groups of patients were substantially improved with respect to baseline but no significant differences between groups were observed. In the patients with asthma no significant changes at all could be registered either in the parents' or in the clinicians' evaluation. No significant differences between the treatment groups were shown in the use of steroid ointments, classified by the most potent class of steroid used (table 5), although there was a trend toward less use of steroid ointments with time in the Epogam group.

Fifty patients were given concomitant medication. Thirty one received additional treatment for their eczema, most of them were given antihistamines. Two were treated with antibiotics for infected eczema. There were no significant differences in drug use between the

Table 3 Parent assessment of eczema

\begin{tabular}{|c|c|c|c|c|c|c|}
\hline \multirow[b]{2}{*}{ Parameter } & \multicolumn{2}{|c|}{ Mean (SE) baseline valuet } & \multicolumn{2}{|c|}{ Mean (\%) improvement from baselinet } & \multicolumn{2}{|c|}{ Differences between treatments $\neq$} \\
\hline & Epogam & Placebo & Epogam & Placebo & Mean§ & $95 \% C I$ \\
\hline $\begin{array}{l}\text { Redness } \\
\text { Dryness } \\
\text { Crusts } \\
\text { Itch } \\
\text { Scaling } \\
\text { Sleep } \\
\text { Fidget } \\
\text { Overall impression } \\
\text { Global assessment }\end{array}$ & $\begin{array}{l}37.2(4.9) \\
42.8(5.3) \\
32.7(5.5) \\
43.1(5.6) \\
23.1(5.4) \\
18.2(4.0) \\
18.0(3.7) \\
39.6(5.6) \\
32.3(4.1)\end{array}$ & $\begin{array}{l}27.8(5.1) \\
38.1(4.4) \\
21.2(3.6) \\
35.4(4.4) \\
17.9(4.7) \\
12.4(3.7) \\
9.2(2.7) \\
27.8(2.9) \\
23.6(2.3)\end{array}$ & $\begin{array}{l}15.1(41)^{\star} \\
14.5(34)^{\star} \\
11.3(35) \\
13.4(31)^{\star} \\
7.5(33) \\
0 \\
1.0(6) \\
12.8(32)^{\star} \\
10.0(31)^{\star}\end{array}$ & $\begin{array}{l}7.4(27) \\
16.6(44)^{\star \star} \\
5.3(25) \\
14.8(42)^{\star \star} \\
5.1(29) \\
1.2(10) \\
-0.3(-4) \\
5.1(19) \\
7.1(30)^{\star}\end{array}$ & $\begin{array}{l}7.8 \\
-2.2 \\
6.0 \\
-1.3 \\
2.4 \\
-1.2 \\
1.3 \\
7.7 \\
2.9\end{array}$ & $\begin{array}{l}-6.3 \text { to } 21.8 \\
-16.9 \text { to } 12.6 \\
-8.9 \text { to } 21.0 \\
-16.1 \text { to } 13.4 \\
-13.6 \text { to } 18.4 \\
-13.0 \text { to } 10.6 \\
-11.4 \text { to } 14.0 \\
-6.3 \text { to } 21.7 \\
-8.8 \text { to } 14.6\end{array}$ \\
\hline
\end{tabular}

$\star 2 \mathrm{p} \leqslant 0.05 ;{ }^{\star \star} 2 \mathrm{p} \leqslant 0.01$.

+ Millimetres on visual analogue scale.

$¥$ A positive value is in favour of Epogam.

None of these mean results was significant.

I Mean of parent assessments.

$\mathrm{CI}=$ confidence intervals. 
Table 4 Clinical assessment of eczema

\begin{tabular}{|c|c|c|c|c|c|c|}
\hline \multirow[b]{2}{*}{ Parameter } & \multicolumn{2}{|c|}{ Mean (SE) baseline valuet } & \multicolumn{2}{|c|}{ Mean (\%) improvement from baselinet } & \multicolumn{2}{|c|}{ Differences between treatments $\neq$} \\
\hline & Epogam & Placebo & Epogam & Placebo & MeanS & $95 \% C I$ \\
\hline Redness & $37.4(3.8)$ & $32.1(2.8)$ & $11.3(30)^{\star}$ & $13.2(41)^{\star \star \star}$ & -1.9 & -13.1 to 9.3 \\
\hline Dryness & $52.4(3.8)$ & $49.6(3.6)$ & $14.8(28)^{\star \star \star}$ & $20.2(41)^{\star \star \star}$ & -5.4 & -16.1 to 5.3 \\
\hline Crusts & $34.5(4.2)$ & $27.4(3.1)$ & $10.0(29)^{\star}$ & $10.0(37)^{\star \star}$ & 0.0 & -11.6 to 11.7 \\
\hline Itch & $47.7(3.5)$ & $42.1(3.1)$ & $13.4(28)^{\star \star}$ & $16.4(39)^{\star \star \star}$ & -3.0 & -15.2 to 9.2 \\
\hline Scaling & $36.4(4.1)$ & $34.8(4.1)$ & $10.1(28)^{\star}$ & $11.2(32)^{\star \star}$ & -1.1 & -11.6 to 9.5 \\
\hline Lichenification & $47.4(4.0)$ & $42.5(3.2)$ & $14.0(30)^{\star \star \star}$ & $18.9(44)^{\star \star \star}$ & -4.9 & -14.7 to 4.9 \\
\hline Fidget & $29.6(3.7)$ & $26.2(3.1)$ & $7.2(24)^{\star}$ & $14.5(55)^{\star \star \star}$ & -7.3 & -15.9 to 1.4 \\
\hline Overall impression & $45.6(3.5)$ & $40.3(2.9)$ & $11.2(25)^{\star}$ & $16.1(40)^{\star \star \star}$ & -4.9 & -16.4 to 6.6 \\
\hline Area involved (\%) & $46.4(4.0)$ & $38.3(3.5)$ & $8.1(17)^{\star}$ & $2.8(7)$ & 5.2 & -4.3 to 14.8 \\
\hline Global assessment & $41.9(3.0)$ & $37.0(2.5)$ & $11.0(26)^{\star \star}$ & $13.8(37)^{\star \star \star}$ & -2.8 & -11.8 to 6.2 \\
\hline
\end{tabular}

$\star 2 \mathrm{p} \leqslant 0.05 ; \star \star 2 \mathrm{p} \leqslant 0.01 ; \star \star \star 2 \mathrm{p} \leqslant 0.001$.

$\dagger$ Millimetres on visual analogue scale.

$\neq$ A positive value is in favour of Epogam.

$\$$ None of these mean results was significant.

I Mean of parent assessments.

$\mathrm{CI}=$ confidence intervals.

Table 5 Steroid usage classified by the most potent class of steroids used (values are number of patients)

\begin{tabular}{llllll}
\hline \multirow{2}{*}{$\begin{array}{l}\text { Most potent steroid group } \\
\text { used }\end{array}$} & \multicolumn{2}{l}{ Epogam } & & \multicolumn{2}{l}{ Placebo } \\
\cline { 2 - 3 } \cline { 5 - 6 } & $1-4$ weeks & $13-16$ weeks & & $1-4$ weeks & $13-16$ weeks \\
\hline I: mildly potent & 15 & 8 & 13 & 12 \\
II: moderately potent & 8 & 13 & 10 & 9 \\
III: potent & 4 & 5 & 3 & 4 \\
IV: very potent & 0 & 0 & 1 & 1 \\
\hline
\end{tabular}

Table 6 Mean (\%) increase from baseline of blood anaylsis of DGLA and arachidonic acid and their total

\begin{tabular}{|c|c|c|c|}
\hline \multirow[b]{2}{*}{ Parameter } & \multicolumn{2}{|c|}{ Mean (\%) increase from baselinet } & \multirow{2}{*}{$\begin{array}{l}\text { Difference between } \\
\text { treatments } \neq\end{array}$} \\
\hline & Epogam & Placebo & \\
\hline DGLA & $0.81(26)$ & $0.12(4)$ & $0.69^{\star \star \star}$ \\
\hline Arachidonic acid & $1.25(12)$ & $0.02(0)$ & $1.22^{\star \star}$ \\
\hline DGLA and arachidonic acid & 1.77 (13) & $0.14(1)$ & $1.63^{\star \star \star}$ \\
\hline
\end{tabular}

$\star \star 2 \mathrm{p} \leqslant 0.01 ; \star \star \star 2 \mathrm{p} \leqslant 0.001$.

+ A positive value denotes an increase.

† A positive value denotes a larger increase for patients receiving Epogam than for those receiving placebo.

patients receiving Epogam and those treated with placebo. In the blood analyses there were highly significant increases in the concentrations of DGLA and arachidonic acid (metabolites of GLA) in the Epogam group (table 6) but no change in the placebo group. When individual patient values for the symptom of itch were plotted against DGLA, arachidonic acid or their total, there was no evidence of a relationship. The routine haematological and biochemical analyses showed only one significant difference between treatments and that was for urate, but all serum urate concentrations remained within the normal range. Five patients receiving Epogam reported five adverse events and six patients in the placebo group reported seven adverse events. None of these was considered as serious and only one in each group as a possible effect of the treatment. All patients achieved a minimum of $87 \%$ compliance over the 16 weeks' treatment period.

\section{Discussion}

The aim of this study was to investigate the effect of GLA on atopic dermatitis and asthma in a study with a significant number of patients. There were only two withdrawals out of 60 patients. Sunflower oil containing a high percentage of linoleic acid was used as placebo because of its similar taste to evening primrose oil and to make it possible to evaluate the specific effect of GLA. In contrast to earlier studies a lot of patients used rather potent steroids of group II and III that might influence the results, as steroids can block the release of fatty acids from phospholipids. Other studies that reported positive effects of GLA have been criticised for obvious baseline differences in disease severity scores in contrast to this study. ${ }^{9-11}$ There are two studies by Biagi and Bordoni et al reporting positive effects. ${ }^{12}{ }^{13}$ The first study was not placebo controlled and includes only 12 children. The other was a parallel group study with 24 children over four weeks. In a meta-analysis on the use of GLA in atopic dermatitis a dose related response was claimed for pruritus. ${ }^{11}$ Our study showed no clinical difference between active and placebo treatment concerning this parameter and there was no evidence of a relationship between serum concentrations of GLA metabolites and the changes in itch score.

The dose of GLA is similar to that given in other recent studies. ${ }^{12-14}$ The compliance was good and the blood analyses showed a highly significant increase in concentrations of DGLA and arachidonic acid in the Epogam group.

In a report by Berth-Jones and GrahamBrown no therapeutic effect of evening primrose oil in atopic dermatitis could be found but this trial can be criticised because no blood tests confirming the compliance were performed. ${ }^{14}$ Bamford et al found no clinical response of primrose oil in a large study that has been criticised as the compliance was poor and the plasma lipid assays showed no increase in the patients allegedly taking Epogam capsules. ${ }^{15}$ There are another two negative reports on the effects of GLA in atopic dermatitis, one with 14 patients ${ }^{16}$ the other with $24 .{ }^{17}$

Atopy and abnormal essential fatty acids also have been linked to hyperactivity. ${ }^{18}$ In this trial we found no clinical effects on fidget in contrast to the results of Guenther and Wexler who, in a report of 14 patients, found that fidget constantly improved during a 24 weeks' study. ${ }^{16}$

The 22 children, who apart from atopic dermatitis also had asthma diagnosed, were well matched. This study found no clinical effect at all on peak expiratory flow or overall impression of asthma, neither with placebo nor with 
Epogam. Ebden et al used evening primrose oil in a double blind placebo controlled study over eight weeks in atopic asthmatics and also found no clinical effect. ${ }^{19}$ There are two negative reports $^{20}{ }^{21}$ with addition of $\mathrm{n}-3$ fatty acids to the diet and one positive, ${ }^{22}$ all with rather limited numbers of patients.

Melnic has proposed that future studies with GLA should include treatment of the atopic mother during pregnancy and lactation as well as her newborn infant. ${ }^{23}$

The improvements could be seen as a substantial placebo response due to the expectations that patients (and parents) have with a new kind of treatment. Another interpretation is more likely as we found no effect whatsoever on the asthma symptoms in the same children. Broberg et al found that children whose parents had received further information and practical training of eczema treatment ('eczema education') improved significantly during a four months' follow up compared with a group receiving routine information. ${ }^{24}$ During our trial we certainly gave our children a closer follow up and extra information, which probably resulted in better local treatment. There was a trend towards use of more potent steroids with time that could support this.

In conclusion our study demonstrated significant improvements in atopic dermatitis during the 16 weeks' treatment, but no significant difference was found between active and placebo treatment in a group of children who need regular treatment with topical steroids. No therapeutic effect on asthma or fidget was shown.

This study was sponsored by Scotia Pharmaceuticals Limited. We thank Mr D Thompson, consultant statistician for Pharmaserve Ltd UK, for statistical advice.

1 Sharpe GR, Farr PM. Evening primrose oil and eczema. Lancet 1990;335:667-8.

2 Horrobin DF, Stewart C. Evening primrose oil and eczema. Lancet 1990;335:864-5.
3 Sharpe GR, Farr PM. Evening primrose oil and eczema. Lancet 1990;335:1283.

4 Horrobin DF, Stewart C. Evening primrose oil and atopic eczema. Lancet 1990;336:50.

5 Hederos C-A. Unorthodox therapy is common among children with allergic disease. Läkartidningen 1988;85:3580-3.

6 Salob S-P, Atherton DJ. Prevalence of respiratory symptoms in children with atopic dermatitis attending pediatric dermatology clinics. Pediatrics 1993;91:8-12.

7 Björksten B. Fatty acids and inflammatory responses-is there a connection ? Acta Paediatr Scand Suppl 1989;351: 76-9.

8 Hanifin JM, Rajka G. Diagnostic features of atopic dermatitis. Acta Derm Venereol Suppl (Stockh) 1980;92:44-7.

9 Wright S, Burton JL. Oral evening-primrose-seed oil improves atopic eczema. Lancet 1982;ii: 1 120-2.

10 Schalin-Karrila M, Mattila L, Jansen CT, Uotila O. Evening primrose oil in the treatment of atopic eczema: effect on primrose oil in the treatment of atopic eczema: effect on
clinical status, plasma phospholipid fatty acids and clinical status, plasma phospholipid fatty acids and
circulating blood prostaglandins. Br $f$ Dermatol 1987;117: circulatin.

11 Morse PF, Horrobin DF, Manku MS, et al. Meta-analysis of placebo controlled studies on the efficacy of Epogam in the treatment of atopic eczema. Relationship between plasma essential fatty acid changes and clinical response. $\mathrm{Br} \mathcal{F} \mathrm{Der}$ matol 1989;121:75-90.

12 Biagi PL, Bordoni A, Masi M, et al. A long-term study on the use of evening primrose oil (Efamol) in atopic children. the use of evening primrose oil (Efamo

13 Bordoni A, Biagi BL, Masi M, et al. Evening primrose oil. Efamol in the treatment of children with atopic eczema. Drugs Exp Clin Res 1988;14:291-7.

14 Berth-Jones J, Graham-Brown RAC. Placebo controlled trial of essential fatty acid supplementation in atopic dermatitis. Lancet 1993;341:1557-60.

15 Bamford JTM, Gribson RW, Renier CM. Atopic eczema unresponsive to evening primrose oil (linoleic and gammalinolenic acids). $₹ \mathrm{Am}$ Acad Dermatol 1985;13:959-65.

16 Guenther L, Wexler D. Efamol in the treatment of atopic dermatitis. $\mathcal{F}$ Am Acad Dermatol 1987;17:860.

17 Rilliet A, Queille C, Saurat JH. Effects of gamma-linolenic acid in atopic dermatitis. Dermatologica 1988;177:257.

18 Colquhoun V, Bunday S. A lack of essential fatty acids as a possible cause of hyperactivity in children. Med Hypotheses 1981;7:673-9.

19 Ebden P, Bevan C, Banks J, et al. A study of evening primrose seed oil in atopic asthma. Prostaglandins Leukot Essent Fatty Acids 1989;35:69-72.

20 Stenius-Aarniala B, Aroo A, Hakulinen A, et al. Evening primrose oil and fish oil are ineffective as supplementary treatment of bronchial asthma. Ann Allergy 1989;62:534-7

21 Kirsch CM, Payan DG, Wong MYS, et al. Effect of eicosapentaenoic acid in asthma. Clin Allergy 1988;18:177-87.

22 Dry J, Wincent $D$. Effect of a fish oil diet on asthma: result of a 1 year double-blind study. Int Arch Allergy Appl Immunol 1991;95:156-9.

23 Melnic BC. Atopic dermatitis and essential fatty acid metabolism. Curr Probl Dermatol 1991;20:215-27.

24 Broberg A, Kalimo K, Lindblad B, Swanbeck G. Parental education in the treatment of childhood atopic eczema. Acta Derm Venereol 1990;70:495-9. 